SHORT COMMUNICATION

\title{
Occurrence of Cryptosporidial Oocysts and Giardia Cysts in Bottled Mineral Water Commercialized in the City of Campinas, State of São Paulo, Brazil
}

\author{
RMB Franco/+, R Cantusio Neto*
}

\begin{abstract}
Laboratório de Protozoologia, Departamento de Parasitologia, Instituto de Biologia, Universidade Estadual de Campinas, Caixa Postal 6109, 13083-970 Campinas, SP, Brasil *Laboratório de Microbiologia, Sociedade de Abastecimento de Água e Saneamento SA, Campinas, SP, Brasil
\end{abstract}

The consumption of bottled mineral water has significantly increased in Brazil so that it is in the interest of public health to determine the parasitological and microbiological status of some brands of Brazilian mineral water available in the town of Campinas, São Paulo, Brazil. For this purpose, detection of protozoa by direct immunofluorescence technique and microbiological parameters were determined for each specimen after membrane filtration. Giardia cysts were not present while cryptosporidial oocysts were detected in two samples. The counts of protozoa varied from 0.2 to 0.5 oocysts/l. The detected level of Pseudomonas aeruginosa and heterotrophic bacteria reflected the level of organic enrichment of the water.

Key words: bottled mineral water - protozoa detection - microbiological parameters - Campinas - Brazil

Water is essential for life but may also become an important vehicle of many parasitic and infectious diseases (with agents of transmission such as bacteria, virus and protozoa), as well as of an increasing frequency of chronic diseases.

Once an emerging pathogen, Cryptosporidium is now firmly established as a widespread cause of enteric disease in humans and other animals. Cryptosporidiosis can be severe especially in the very young, the aged, the nutritionally deficient, and life-threatening in those whose immune systems may be compromised by disease or therapeutic agents. In Aids patients, Cryptosporidium contributes to death and no drug therapy has been found to be effective for this infection (Fayer et al. 2000). Transmission of oocysts excreted from infected hosts occurs either by direct host-to-host contact or indirectly by ingestion of contaminated water or food.

Giardia is a flagellated protozoan that causes clinically significant intestinal disease in humans as well as in livestock (Meyer 1990). Due to its increasing role in outbreaks of diarrhea among children attending day-care centers (Thompson 1994, Franco 1996) Giardia is now referred to as a re-emerging infectious agent (Thompson 2000). In this type of host G. duodenalis promoted a variety of symptoms such as diarrhea, weight loss, abdominal cramps, and growth stunt. This pathogen shares similar epidemiological features with Cryptosporidium, and giardiasis along with cryptosporidiosis represent one of

${ }^{+}$Corresponding author. Fax: $+55-19-3289.3124$. E-mail: fllanos@bestway.com.br

Received 25 July 2001

Accepted 13 September 2001 the major public health concerns regarding water utilities today (Thompson 2000).

Since these protozoa were registered in ground and raw water (Gamba et al. 2000, Franco et al. 2001) in the State of São Paulo, Brazil, the detection of Cryptosporidium and Giardia in mineral water from natural sources provides an interesting area of research because the consumption of bottled mineral water has registered great increase in the last decade, with the State of São Paulo as the principal producer (Eiroa et al. 1996, Abinam). In addition, the presence of microbiological indicators marked the need for cysts and oocysts detection due to the possibility of contamination (Ministério da Saúde 2000).

The present work was carried out to verify the parasitological (Cryptosporidium, Giardia) and microbiological status of some Brazilian mineral water brands commercially available in the city of Campinas, São Paulo, Brazil.

Duplicate samples of 13 bottled brands of non-gaseous mineral waters (20 1; exception of L12-vol. 1.5 1) were submitted to filtration (4 1/min) in 45-mm-diameter-sterile cellulose acetate membranes (Schleicher \& Schuell, Brazil), with nominal porosity of $3 \mu \mathrm{m}$. Afterwards, the filters were transported in refrigerated plastic containers to the Protozoology Laboratory, Parasitology Department, Campinas State University and were cut in two parts. Samples elution was performed by (i) alternately scraping the membrane with a smooth-edged plastic loop and rinsing it with $0.1 \%$ Tween 80 elution solution (RM method) (Shepherd \& Wynn-Jones 1996) and (ii) the acetone-dissolution (ADM method) (Graczyk et al. 1997), respectively. The pellets were obtained by centrifugation ( $15 \mathrm{~min} ; 600 \mathrm{x}$ g) and diluted to $1 \mathrm{ml}$ with $0.22 \mathrm{~mm}$ water filter system (MilliQ, Millipore, Brazil). One or more aliquots $(5 \mu \mathrm{l})$ of these pellets were examined by direct immunofluorescence 
(Merifluor kits; Meridian Diagnostics, Cincinnati, Ohio) and simultaneously by phase contrast microscopy. The Zeiss Axiolab epifluorescent microscope with a 450-490 $\mathrm{nm}$ excitation filter and a $520 \mathrm{~nm}$ barrier filter was used to read the reaction.

Microbiological parameters were determined for each specimen (Escherichia coli or thermotolerant (fecal) coliforms, Enterococcus and Pseudomonas aeruginosa) according to methodology recommended by Standards Methods for the Examination of Water and Wastewater (APHA 1995) and by the Brazilian legislation for mineral waters (Resolution RDC no. 54).

A control trial was performed to evaluate the recovery efficiency of the methods employed by placing a known number of seed oocysts (from a suspension of oocysts obtained from fecal samples of HIV-infected patients, University Hospital, State University of Campinas - " $\mathrm{CH}$ isolate"), and cysts/oocysts (Easy-Seed; Biotechnology Frontiers, Australia) in a similar volume of mineral water previously filtered in $1.2 \mu \mathrm{m}$ membrane. A small volume (2 1) was also submitted to membrane filtration; this assay was conducted twice for " $\mathrm{CH}$ isolate" and, finally, all pellets resulting (experimental and control samples) were numerated again prior to microscopy analysis (blinded assay).

In this survey, 13 bottled brands of non-gaseous mineral waters were analyzed; these labels are among the most popular in supermarkets in the city of Campinas. Cryptosporidium oocysts were detected in two water labels (L6 and L7) but Giardia cysts were not present in the water brands included in this study, in spite of the method employed (RM or ADM; Table I). It is noteworthy that L6 showed positiveness on two occasions. The counts of protozoa varied from 0.2 oocyst/l to 0.5 oocyst $/ 1$. The detected oocysts are in conformity with standard fluorescence detection criteria (Connel et al. 2000) and contrastphase microscopy carried out simultaneously at magnification of 400 and 1,000x; when possible sutures and other morphologic features compatible with Cryptosporidium were observed in these forms. The results of the control trial are shown in Table II.

As regards microbiological parameters, three samples (L8, L10, L11) (Table I) presented positiveness for $P$. aeruginosa and consequently did not comply with the standard potability values foreseen in the existing Brazilian resolution, although the same resolution recommends collection of significant samples before they are accepted. High densities of heterotrophic bacteria in all analyzed samples (Table I) point out to the level of organic enrichment of the water.

Concerning the efficiency of recovery of cysts and oocysts (Table II), the RM method was better than the $\mathrm{ADM}$ technique, as had already been shown in a previ-

TABLE I

Results of Cryptosporidium oocyst and microbiological analysis ${ }^{a}$ of some brands of Brazilian mineral water commercially available in the city of Campinas, São Paulo, Brazil

\begin{tabular}{|c|c|c|c|c|c|c|}
\hline \multirow{2}{*}{$\begin{array}{l}\text { Samples } \\
\text { (brand/sample) }\end{array}$} & \multicolumn{5}{|c|}{ Microbiological analysis } & \multirow[t]{2}{*}{ Cryptosporidium oocysts ${ }^{a}$} \\
\hline & $\mathrm{C}_{\mathrm{T}}$ & $\mathrm{C}_{\text {TERM }}$ & $\mathrm{CPBH}_{\mathrm{ufc} / \mathrm{ml}}$ & P. $a$. & $E$. & \\
\hline L1.(S1) & A & A & $>6500$ & $\mathrm{~A}$ & $\mathrm{~A}$ & A \\
\hline L1.(S2) & A & A & $>6500$ & A & A & A \\
\hline L2.(S1) & A & A & 980 & $\mathrm{~A}$ & $\mathrm{~A}$ & A \\
\hline L2.(S2) & A & A & 100 & A & A & $\mathrm{A}$ \\
\hline L3.(S1) & A & A & $>6500$ & A & A & A \\
\hline L3.(S2) & A & $\mathrm{A}$ & $>6500$ & A & $\mathrm{A}$ & A \\
\hline L4.(S1) & $\mathrm{A}$ & $\mathrm{A}$ & $>6500$ & $\mathrm{~A}$ & $\mathrm{~A}$ & A \\
\hline L4.(S2) & A & A & 300 & A & $\mathrm{A}$ & A \\
\hline L5.(S1) & A & A & $>6500$ & A & A & A \\
\hline L5.(S2) & A & $\mathrm{A}$ & $>6500$ & A & $\mathrm{A}$ & A \\
\hline L6.(S1) & A & A & 800 & A & A & $\mathrm{P}$ \\
\hline L6.(S2) & A & A & $>6500$ & A & A & $\mathrm{P}$ \\
\hline L7.(S1) & A & A & 100 & A & A & A \\
\hline L7.(S2) & A & A & 10 & $\mathrm{~A}$ & A & $\mathrm{P}$ \\
\hline L8.(S1) & A & A & $>6500$ & 16 & A & A \\
\hline L8.(S2) & A & $\mathrm{A}$ & 650 & A & A & A \\
\hline L9.(S1) & A & A & 30 & A & A & A \\
\hline L9.(S2) & A & $\mathrm{A}$ & 10 & A & $\mathrm{A}$ & A \\
\hline L10.(S1) & A & A & $>6500$ & A & A & A \\
\hline L10.(S2) & A & A & $>6500$ & 23 & A & A \\
\hline L11.(S1) & A & A & $>6500$ & A & A & A \\
\hline L11.(S2) & A & A & $>6500$ & $>23$ & A & A \\
\hline L12.(S1) & A & A & 10 & A & A & A \\
\hline L12.(S2) & A & A & 120 & A & A & A \\
\hline L13.(S1) & A & A & $>6500$ & A & A & A \\
\hline L13.(S2) & A & A & $>6500$ & A & A & A \\
\hline
\end{tabular}

a: Giardia were not detect in the analyzed water; $\mathrm{C}_{\mathrm{T}}$ : total coliforms $(\mathrm{NMP} / 100 \mathrm{ml}) ; \mathrm{C}_{\mathrm{TERM}}$ : Escherichia coli or thermotolerant (fecal) coliforms (NMP/100 ml); $\mathrm{CPBH}_{\mathrm{ufc} / \mathrm{ml}}$ : heterotrophic bacteria; P.a.: Pseudomonas aeruginosa; E: Enterococcus; A: absence; $\mathrm{P}$ : presence 
TABLE II

Efficiency rates (\%) of recovery of cryptosporidial oocysts and Giardia cysts in control-trial

\begin{tabular}{lccc}
\hline & \multicolumn{2}{c}{ Samples inoculated with } \\
\cline { 2 - 4 } Elution & $\begin{array}{c}\text { Cryptosporidium } \\
\text { method }\end{array}$ & \multicolumn{2}{c}{ Easy-seed ${ }^{b}$} \\
\cline { 2 - 4 } & $(\mathrm{CH})^{a}$ & Cryptosporidium & Giardia \\
ADM & $30.0-36.0$ & 20 & 4 \\
RM & $90.0-91.8$ & 20 & 91.8 \\
\hline
\end{tabular}

a: CH isolate"; two experiments; number of seed oocysts: 16/ 1; $b$ : Easy-seed (Biotechnology Frontiers, Australia), according to manucfaturer instructions; one experiment; number of seed oocysts: $99 \pm 2 / 21$; number of seed cysts: $98 \pm 1.6 / 21$; ADM: acetone-dissolution membrane; RM: rinsing membrane

ous study (Franco et al. 2001). The ADM procedure has the disadvantage of inducing the hardening of the pellet containing oocysts or cysts after the centrifugation step.

The findings obtained in this study are very important since recently published surveys reported that people drank bottled water because they believed it meant "drinking water of better quality" and "safe" (Anadu \& Harding 2000) and this may be not the case. The level of oocysts detected in this survey is sufficient to cause infection; the ID $_{50}$ for human volunteers ranged from 9 to 1,042 oocysts, depending on the isolate (Fayer et al. 2000) and because various genotypes were recently identified causing human infection as C. muris (Katsumata et al. 2001), C. meleagridis and C. felis/C. "dog” (Xiao et al. 2001, Pedraza-Díaz et al. 2001) it is more prudent to consider any oocyst present in water for human consumption as offering risk of cryptosporidiosis, principally for HIV/Aids subjects, when the use of molecular tools is not possible.

\section{REFERENCES}

APHA-American Public Health Association 1995. Standard Methods for Examination of Water and Wastewater, 20th ed., AWWA, WEF, Washington, D.C.

Anadu EC, Harding AK 2000. Risk perception and bottled water use. AWWA 92: 82-92.

Abinam-DNPM Associação Brasileira da Indústria de Águas Minerais/Departamento Nacional de Produção Mineral, http://www.abinam.com.br

Connel K, Rodgers CC, Shank-Givens HL, Scheller J, Pope
ML, Miller K 2000. Building a better protozoa data set. AWWA 92: 30-43.

Eiroa MNU, Junqueira VCA, Silveira NFA 1996. Avaliação microbiológica de linhas de captação e engarrafamento de água mineral. Ciênc Tecnol Aliment 16: 165-169.

Fayer R, Morgan U, Upton SJ 2000. Epidemiology of Cryptosporidium: transmission, detection and identification. Int J Parasitol 30: 1305-1322.

Franco RMB 1996. Infecções Parasitárias em Creches: Estudo em uma Área Urbana, com Ênfase em Cryptosporidium parvum e Giardia duodenalis, $\mathrm{PhD}$ Thesis, Unicamp, 104 pp.

Franco RMB, Rocha-Eberhardt R, Cantusio Neto R 2001. Occurrence of Cryptosporidium oocysts and Giardia cysts in raw water from the Atibaia River, Campinas, Brazil. Rev Inst Med Trop São Paulo 43: 107-109.

Gamba RC, Ciapina EMP, Espíndola RS, Pacheco A, Pellizari VH 2000. Detection of Cryptosporidium sp. oocysts in groundwater for human consumption in Itaquaquecetuba city, São Paulo, Brazil. Bras J Microbiol 31: 151-153.

Graczyk TK, Fayer R, Cranfield MR, Owens R 1997 Cryptosporidium parvum oocysts recovered from water by the membrane filter dissolution method retain their infectivity. J Parasitol 83: 111-114.

Katsumata T, Hosea D, Ranuh IG, Uga S, Yanagi T, Kohno S 2000. Short report: possible Cryptosporidium muris infection in humans. Am J Trop Med Hyg 62: 70-72.

Meyer EA 1990. Preface and Editor's note, in Giardiasis, Elsevier.

Ministério da Saúde, 2000. RDC n 54, 15/6/2000.

Pedraza-Díaz S, Amar C, Iversen AM, Stanley PJ, McLauchlin J 2001. Unusual Cryptosporidium species recovered from human faeces: first description of Cryptosporidium felis and Cryptosporidium "dog type" from patients in England. J Med Microbiol 50: 293-296.

Shepherd KM, Wynn-Jones AP 1996. An evaluation of methods for the simultaneous detection of Cryptosporidium oocysts and Giardia cysts from water. Appl Environ Microbiol 62: 1317-1322.

Thompson RCA 2000. Giardiasis as a re-emerging infectious disease and its zoonotic potential. Int J Parasitol 30: 12591267.

Thompson SC 1994. Giardia lamblia in children and the child care setting: a review of the literature. J Paediatr Child Health 30: 202-209.

Xiao L, Bern C, Limor J, Sulaiman I, Roberts J, Checkley W, Cabrera L, Gilman RH, Lal AA 2001. Identification of 5 types of Cryptosporidium parasites in children in Lima, Peru. J Infect Dis 183: 492-497. 
